\title{
Building our worlds: co-developing future scenarios as a methodology for fashion researchers and designer-innovators
}

\author{
Dilys Williams ${ }^{a}$, Laetitia Forst ${ }^{a *}$, Doroteya Vladimirova ${ }^{b}$, Steve Evans ${ }^{b}$ \\ aUniversity of the Arts London \\ bUniversity of Cambridge \\ *Corresponding author e-mail: l.forst@arts.ac.uk
}

\begin{abstract}
:
In the context of climate and social injustice at global and local scales; commitment to change is being translated into resource efficiency and problem-minimising activities. These actions are not enough to make a required radical shift from the current trajectory of fashion industry-related impacts. This paper presents interim insights from collaborative research, undertaken by academic researchers with designer-innovators, in designing context, over designing in the current context of fashion. Thus product, services and business models are part of transformation design that extends the value of fashion's social, economic, environmental, and cultural dimensions. Designing is an iterative, dynamic process, responding and shaping context, based on key concerns and areas of interest and opportunity. The research describes a scaffolding of context through a scenarios methodology, in which participants are co-contributors, practicing in flux, designing products, services, systems, and contexts in which we might thrive together.
\end{abstract}

Keywords: transformation design, scenario building, industry collaboration, fashion design

\section{Introduction: creating a safe environment to tackle sustainability challenges}

This paper presents interim findings from collaborative research that explores scenario development as a methodology for design and business model transformation. Creating conditions for mutual learning between academia and industry, it seeks to create new knowledge and support fashion design businesses in sustainability research and development. 


\subsection{Environmental challenges for fashion industry require radical approaches to change.}

It is widely acknowledged that the fashion sector is a major contributor to the pressure on planetary boundaries, and that whilst the industry plays a crucial role in cultural and economic narratives, the trajectory of its impacts shows a dramatic increase over the coming decades, diametrically opposed to global goals (World Resources Institute, 2017). Radical change is needed for the positive aspects of fashion to be sustained without contributing to increasing environmental challenges. (Ellen MacArthur Foundation, 2017; Global Fashion Agenda, 2017). In short, “...current solutions and business models will not be sufficient to deliver on the current climate agenda. Fashion industry needs to embrace a deeper, more systemic change..." (United Nations Climate Change, 2018).

This research takes a transformation design approach, as part of a radical shift in perception, strategy, product and business model development. Transformation design recognises that all actions take place in a living system, thus change is ongoing. It is the direction and depth of change that matters, 'the challenge is not how to design a response to a current issue, but how to design a means of continually responding, adapting and innovating' (Burns et al., 2006). Transformation design seeks to leave behind not only the shape of a new solution, but the tools, skills, and organisational capacity for ongoing change (Burns et al., 2006, p. 21).

The scenario methods proposed in this paper offer a way of projecting into complex and unpredictable futures to imagine resilience and a positively transformed industry. Designers need to understand the complex dynamic processes used to manufacture products and systems as coevolving processes (Fuad-Luke, Hirscher and Moebus, 2015). The dramatically heightened complexity of designing fashion in the context of the climate emergency, requires a close connecting of what and how to design and innovate.

\subsection{Re-modelling Fashion}

Re-Modelling Fashion connects researchers with expertise in design and business models with fashion industry design professionals. The aim of the project is to provide tools that enable a transformation of the fashion sector through radical approaches to product value and product service systems. This paper offers findings from an initial phase of the research, with three small and medium sized fashion enterprises (SME), as part of a larger research programme spanning codevelopment with design teams within a large fashion company, as well as with masters' students, to progressively iterate the methodology presented here. Re-Modelling Fashion project is also part of a multi-disciplinary research UKRI funded clusters project, seeking to deliver R\&D in sustainable innovation with and for the UK creative industries. The research described here sought to create a safe space for designer-innovators to be supported in taking part in experimentation that challenges conventional models for design, acquisition and use of garments. This is enabled through participatory design practices and a recognition of time and financial constraints. The programme therefore includes provision for financial support and mentoring for the small businesses involved.

The three designer-innovators are pioneers in their fields with visions for regenerative fashion, business models for changed acquisition practices and material and product innovation; they are already at the forefront of remodelling fashion in the context of sustainability. They are hyper-agile, with sustainability values in their DNA, so an appropriate testing ground for exploring radical transformation. As a group they offer distinctive, whilst connected views on the sector and its 
challenges. Selection to the programme was realised through a call out for submissions and review by an independent panel, using criteria relating to the overarching project, to create demonstrator projects and build an R\&D infrastructure.

Participants are researchers and designer-innovators, who create and use a dynamic, ongoing, scenario methodology to stimulate and test product and service innovations. This paper presents early-stage development of this methodology. As such, we offer ourselves up to the vulnerabilities that accompany working with a beta format, whilst seeking to share insights from an initial framework that can be useful and transferable within and well beyond the project itself.

\subsection{Co-enquiry between academia and industry}

This research inquiry into methods and practices for transformation design, to extend the value of fashion, references co-operative inquiry, an approach that seeks to:

- Understand the world and develop new and creative ways of looking at things;

- Learn how to take action to change things and find ways to do things better.

(Heron and Reason, 1986)

It is research and exploration that is conducted with- rather than on- people, bringing together participants with connected interests and distinctive expertise. This inquiry is concerned with revisioning our understanding of the world, as well as transforming practice within it (Heron and Reason, 2001). All involved in the project are co-researchers and co-subjects.

This approach to collaboration between industry and academia transcends the usual case study or knowledge exchange model. It adopts an engaged scholarship research strategy as a participatory form of research, which is designed to work across the theory-practice boundary (Van de Ven, 2007). The collaboration is designed as a mutual exchange, and the programme set up to share expert knowledge, to support the designer-innovators in their designing, whilst gathering their input to inform research to create original insights for wider benefit.

\section{Scenarios}

One way of considering design that expands beyond activities taking place within a context, towards design of context, is through the creation of scenarios, and the development and testing of products within them.

\subsection{Cross-disciplinary relevance in transformation design}

There is a well-articulated understanding of the use of scenarios work in business, for ideation, risk management and in research for innovation and in environmental work, including by the Club of Rome in Limits to Growth (UN, 1972). For the design researchers in the project, taking a cultural approach to scenarios involves creating stories of the future that can provoke, engage, and elicit feedback relating to how and what we design and our understanding of interdependencies between elements of life. Design for sustainability discourse explores sense-making as well as form-making (Williams, 2018, Manzini, 2015, Walker and Giard, 2013) and scenarios prepare us perceptually (to create visions and practices) and practically (to create products and business models). 
For designers, it is the origin of scenarios in sixteenth century theatre, usually associated with improvised performances of Commedia dell'arte, that is, perhaps of particular interest. A pinned-up scenario, back-stage, typically offering location, set of people, relationships, and props, would act as the basis for responding to the unforeseen (Tyszczuk, 2019). Ideas of improvisation date back to Aristotle, but are particularly apt in times where we cannot fix problems using the same logic that was used in creating the ecological crisis.

Scenarios are valuable tools in pre-conceptualising transformation and opening a perspective into new paradigms. Co-creating scenarios with design and business model researchers and designerinnovators can enhance an inspiration and ideation process. They are also instrumental in developing strategies for change with higher chances of implementation (Hebinck et al., 2018). Scenarios methodologies require a form of openness to weak signals and to challenge accepted ways of 'searching' for what is known or wanted (Carney, 2018). The process involves gathering information about emerging trends, exploring how these might evolve and combine and what impact they might have on the future. This relies on multiple sources of information, mixing desk-based research and workshop discussions (Government Office for Science, 2017).

Future scenarios are widely used as probes to expand perspectives across different industries. Some are geared towards tracing trajectories to avoid, or live with, climate and societal collapse (Randers et al., 2018; Arup, 2019) or look at how customer habits may change in a specific sector (Sainsbury's and Department 22, 2019; Future Today Institute, 2020). For fashion, the Fashion Futures 2030 scenarios consider how shifting environmental and social challenges and values will be represented in dress (Centre for Sustainable Fashion, 2018). Most of these examples narrate a vision to inform organisation and design decisions, helping in imagining products and services that can respond to any context, or assist in future-proofing current offers. In this work, rather than providing readymade scenarios to the participants, the research team co-created themes and scenarios that offer a relevant representation of the challenges and opportunities for fashion businesses. The methodology for scenario planning was thus laid bare and shared with the designer-innovators to engage in. The value of this approach is partly in breaking away from traditional approaches to scenario building in which current observations and mega-trends are assembled into a story for designers to use as a starting point. Instead, the research presented here attempts to liken the scenario building method to that of the design inspiration phase, or mood board making. This involves designers in the process of framing what could be taking place and what customers might be experiencing, in relation to products, using creativity to engage in future possibilities for fashion, factored into the earliest stages of product ideation processes.

\subsection{Critical uncertainties}

The themes for the scenarios emerged from a research ideation process involving a literature review, detailed case studies of over 30 examples of pioneering fashion businesses and initiatives, a review of over 150 cases of sustainability-led businesses, and co-design amongst the research team. This open search for signals of change, akin to horizon scanning methods (Government Office for Science, 2017) connects closely to the inspiration phase in creative design processes (Design Council, 2021). By identifying weak signals of change in the cases and literature, the team grouped multiple indicators of radical change into clustered categories which, through an iterative process of synthesis and review, culminated in identifying four themes, agreed as promising in their ability to provoke, stimulate and steer design and business-model innovation. The identification of themes to guide the creative process is a key step in fashion design (Cassidi, 2011), creating edges or boundaries for 
design. In this case, the approach is adapted and extended beyond aesthetic and current market considerations to involve environmental and societal questions at the outset of the inspiration phase. The themes offer provocations, as first stones in a co-developed framework for scenario building towards radically re-conceptualised products and practices. They imagine beyond the usual parameters of design, whilst maintaining practical dimensions of product application. They can then be used as relevant corner stones in developing future scenarios as described in the following sections. Scenarios are extrapolations of possibility, they are not predications plotting out singular intentions, or knowing in advance, (an understanding of interdependencies busts the myth of fixed knowledge) but by defining critical uncertainties, design is informed and expanded into new realms.

The four emerging themes from the researcher co-design process:

- Regeneration reaches beyond sustainability into regenerating systems - industrial, economic, social, and cultural, to repair and heal damage to natural and social ecosystems.

- Trust explores cultures, relationships and systems of sharing information and resources.

- Geography considers a spectrum that runs between hyper-local, place-based communities and ultra-globally based systems, enabled connectivity and accessibility.

- Power explores representation and equity of all stakeholders, including society and nature.

These themes were then combined into scenario matrices with illustrated examples to provide a starting point for discussion and ideation in the workshop series with researchers and designerinnovators. Alongside the visualisation of the scenarios, a set of questions were developed to stimulate radical thinking. Refining and converging broad questions into defined priorities enables structured discussion that can foster meaningful and transformational creativity and product innovation.

\subsection{Scenario matrices}

The methodology for scenario building defined by Peter Schwartz (1991) offers clear steps that balance the open-ended ideation with a rapid-prototyping process to: first identify two critical uncertainties, then identify what represents a 'low' and a 'high' for each uncertainty, to then allocate uncertainties to two axes of a cross, with low and high on each end. The matrix thus delineates four scenarios, one in each quadrant, combining an extreme for each critical uncertainty. The scenarios can then be fleshed out to include titles and stories to represent how the conjunctions of the two variables can paint a picture than can steer design and decision-making processes. 


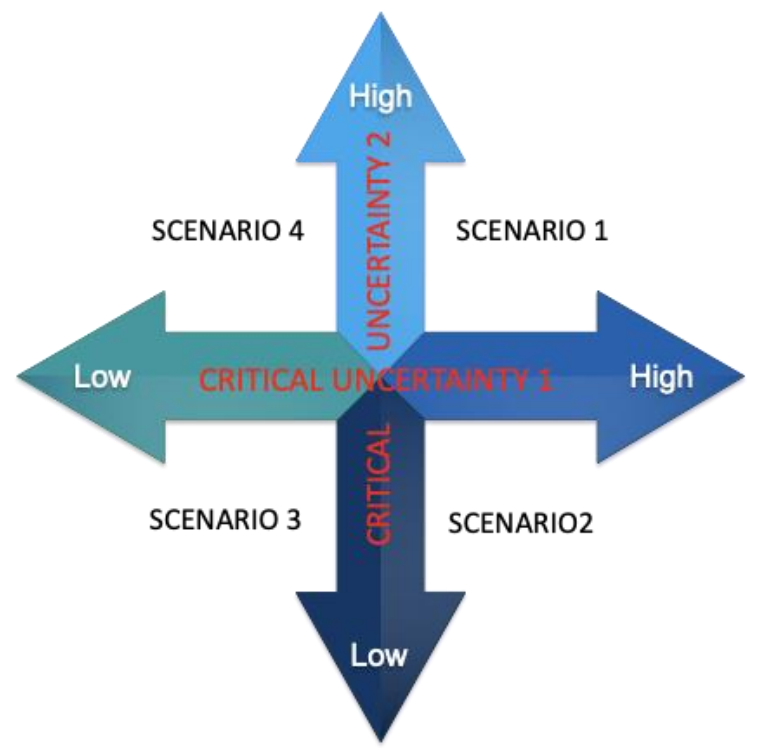

Figure 1. Scenario Planning 2x2 Matrix (Schwartz, 1991)

This framework for scenario development is a guiding aspect of the methodology shared with designer-innovators to co-develop scenarios. Ahead of engaging the teams in workshops, the research team undertook a process of testing the four themes and their respective extremes. This led to the development of two separate matrices that combine two themes each. As shown in figure 2 and 3 , the critical uncertainties are presented within the two matrices. These combinations were selected, through the co-design process, as the most relevant in supporting meaningful conversations in the workshop series, which then led to refining and adapting the two matrices.

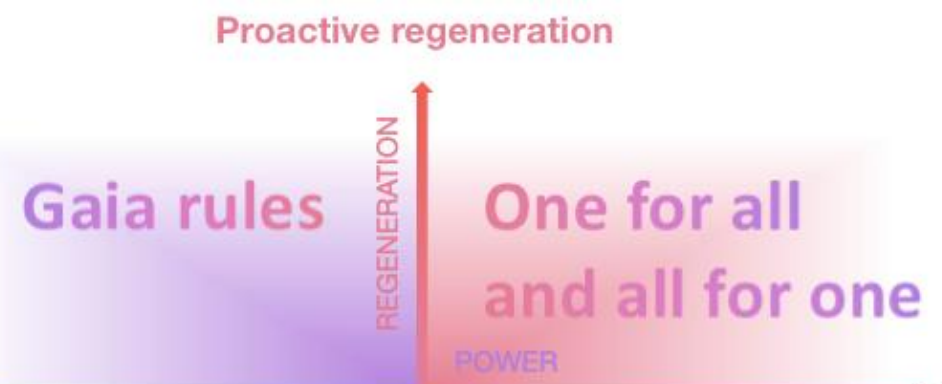

Centralised

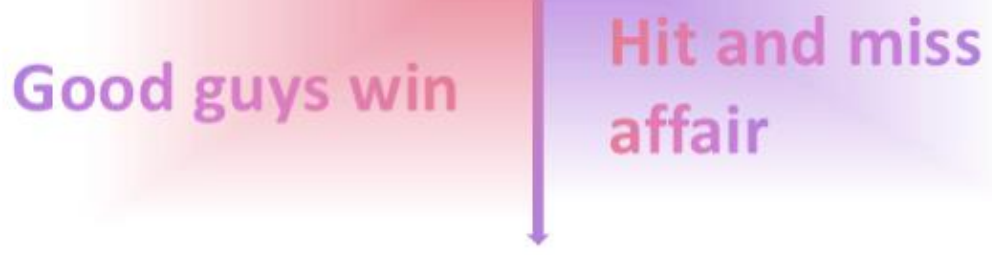

Damage mitigation

Figure 2. Regeneration $x$ Power scenario matrix 


\section{Trust based system}

\section{Street party}

$\frac{5}{8}$

Local

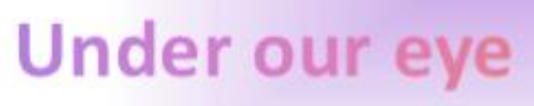

Information

superhighway

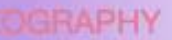

\section{Skeptic system}

Figure 3. Trust $x$ Geography scenario matrix

\section{Co-created scenarios}

The aim of the collaboration is to use the experience of the designer-innovators to refine the scenarios through a series of workshops and to produce an iterated framework that can be transferred to other settings.

\subsection{Workshop design}

Collaboration is enacted through a series of participatory workshops, mixing one-to-one discussions between researchers and each designer-innovator team separately, plus sessions involving all parties. The term workshop is applied to a session in which the business and academic teams came together, using techniques of co-operative enquiry, to progress the work set out at the start of the project. Further informal meetings between workshop sessions were also planned to give continuous support to the businesses. Table 1 shows the programme and aims of each workshop.

Table 1. Workshop programme

\begin{tabular}{lll}
\hline Date & Programme & Aims \\
\hline $\begin{array}{l}\text { December } \\
2020\end{array}$ & $\begin{array}{l}\text { Workshop 1: 1 to 1 mentoring and } \\
\text { needs analysis, shaping the individual } \\
\text { projects targets }\end{array}$ & $\begin{array}{l}\text { Analyse the needs and } \\
\text { aspirations of each business }\end{array}$ \\
\hline
\end{tabular}




\begin{tabular}{lll}
\hline $\begin{array}{l}\text { February } \\
2021\end{array}$ & $\begin{array}{l}\text { Workshop 2: Collaborative } \\
\text { brainstorming session using the } \\
\text { scenario matrices }\end{array}$ & $\begin{array}{l}\text { Brainstorm in the scenario } \\
\text { framework }\end{array}$ \\
\hline June 2021 & $\begin{array}{l}\text { Workshop 3: 1 to 1 value proposition } \\
\text { building workshop }\end{array}$ & $\begin{array}{l}\text { Explore business models and } \\
\text { stakeholder networks }\end{array}$ \\
\hline July 2021 & $\begin{array}{l}\text { Workshop 4: Internal presentation to } \\
\text { project stakeholders }\end{array}$ & Present completed prototypes \\
\hline $\begin{array}{l}\text { September } \\
2021\end{array}$ & $\begin{array}{l}\text { Workshop 5: Collaborative discussion } \\
\text { on the full process of the project }\end{array}$ & $\begin{array}{l}\text { Reflect on the full process and } \\
\text { the impacts of the scenario work }\end{array}$ \\
\hline
\end{tabular}

As the programme is a 'work-in-progress', this review focusses on the insights from the initial phase of workshops. The aims were to expand the inspiration phase and support the development of transformative product service systems for each business. Then to conceive ideas and to sense-check them in the context of the scenarios. For the research team, these sessions were also to collaboratively review the scenario matrices and test their validity in supporting radical ideation. As part of the co-enquiry, the workshops were set up to share and develop experiential knowing, via experience and discourse, presentational knowing, via visual aspects of the prepared scenario work and propositional knowing through the articulation of ideas.

After workshop 1 outlining the needs and plan for each designer-innovator's project, the scenario matrices were used in a longer session in workshop 2, engaging all designer-innovators together in a deeper version of the process outlined above. Here they were asked to dive into the stories for each scenario and flesh them out with references that correlated with their own work. The participants were able to safely discuss core concerns and ideas when setting out to be speculative and experimental in this field, informed by each other's insights, whilst each able to remain confident that their product ideas were very much their own work.

\subsection{Refined scenario tools}

The outcome of this phase and review of the participants' comments, is a revised scenario matrix, reflecting more accurately the relationships between themes and how they can be useful in a transformation design process. In workshop 2 ,it was noted that some themes resonated clearly, with common challenges, whereas others were less beneficial in contributing to the discussion. The theme of Regeneration, discussed from a range of understandings, was recognised as a standout and unchallenged 'common aim'. It was therefore recognised as a direction infusing all decisions, rather than being placed on an axis with a scale from high to low. Therefore, it was removed from the matrix and considered as an overarching context of design. The workshop highlighted a tension between localism as a sustainability strategy and the growing globalisation of communications as central to business decisions. Thus, a horizontal axis was created to support extremes of the Geography theme. Power was explored through divergence, and convergence, narrowed down to the concept of control, as the counterpart to trust which was a key theme for designer-innovators. In this new vertical axis, control and trust are presented as opposites, as they imply different approaches to collaboration, representation, and trading practices. At one end control suggests a scenario with strong regulation, opening up questions about ownership and intentions relating to control. Conversely, trust suggests a lesser need for audits and regulation in an open sharing system. 


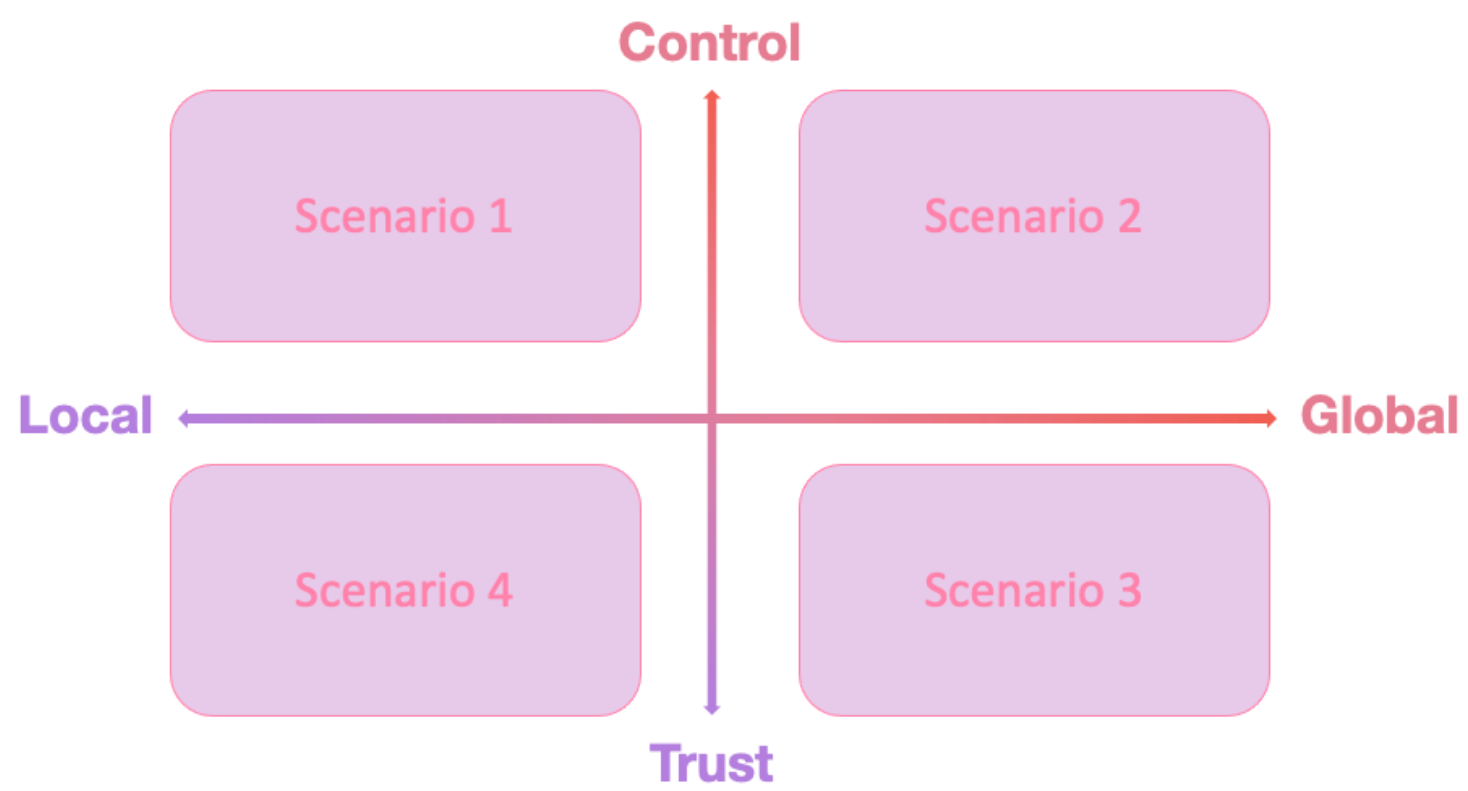

Figure 4. Iterated scenario matrix

The aim of this research phase is to test and refine the scenario building methodology so that it can be applied in other contexts at other scales of activity - across a range of business types, sizes and locations, from start-ups to multinational organisations. Understanding the perspectives of participants was vital in developing a framework that can be relevant to a range of businesses to explore radical new fashion practices. The initial phase designer-innovators are currently in the process of developing prototypes, that will act as outputs that can be reviewed in relation to previous products by the same teams. Using the safe space of the co-enquiry and supported by project funding, and a complementary dimension of cooperative enquiry, practical knowing through doing and making will be supported in workshops 3-5. The final outputs will then be discussed and reviewed against previous work by the same teams.

This beta tool, developed between researchers and designer-innovators, builds on an initial research phase, which was undertaken with MA students as an initial test phase, before the designerinnovator phase described above. The third stage of research will involve designer-innovators in a large-scale business with design, manufacture and retail in multiple global locations. Finally, outputs from all three phases will be reviewed and discussed with the participants, to better understand the impact of the collaborative process of scenario-making and its use in product and service design.

\subsection{Tools for designers}

Current assessment for sustainability heavily relies on quantitative measurements of impact reduction for design decisions such as material switches or improved logistics. While these considerations are important, this work argues that a shift in mindsets and a reappraisal of values is required. Yet few design for sustainability tools currently provide this level of thinking. Kozlowski, Bardecki and Searcy (2019) argue that good tools for fashion design for sustainability should consider an expanded role of the designer, acknowledging their strategic role in transformation design as well as speaking the language of visual and interactive media. Instinctively, the scenario approach touches on a designer's ability to imagine and create new worlds. Designers are used to inventing stories, 
whether through the creation of personas (Miaskiewicz and Kozar, 2011), or of mood boards (Cassidy, 2011). Imagining and visualising external forces that drive needs, habits and aspirations and responding to them with relevant products and services is an inherent part of the designer's skill set. This research proposes that by front-ending the design process with a deep reflection on the challenges and drivers for sustainability, true transformation can be enabled. The scenarios are therefore a means for designers and others to be prepared for, and to create, what might be, to create contexts as well as products and to act in ways that regenerate, repair and contribute positively in the world.

\section{Conclusion and next steps}

This interim paper presents a key step in the development of scenario building tools to support transformation design practices in the fashion sector from the earliest stage. By actively engaging in co-inquiry with researchers and designer-innovators in the scenario development process, a framework is enriched by the lived experiences of all involved. The first two of five workshops on which this paper reports provided a safe environment for each participant to question their practice at core and exchange challenges and opportunities they are facing in their work. Simultaneously, this discussion provided the research team with key insights to refine the scenario matrix and move it a step further to becoming a tool that can be used and applied to transformation design processes. A key approach in this work is to use designers' tacit knowledge, knowing more than we can tell (Polanyi, 1967) using conceptual information and images to communicate understanding of processes and challenges. This is brought to life in the scenario building tool and methodology.

This approach can be applied in a range of practices, by adapting the content to relevant challenges and holding conversations with stakeholders inside this framework. In the next steps of the project, the designer-innovator prototypes will be reviewed to demonstrate how this thinking has been embodied in transformative products and services. Simultaneously, the iterated scenario framework will be used in the third phase workshops with a large-scale brand and then, to complete the actionreflection process, it will again be carried out with masters' students to further test its potential as an essential part of a transformative approach to fashion design for sustainability.

\section{References}

Arup (2019) Four Plausible Futures: 2050 scenarios. Available at: https://www.arup.com/perspectives/publications/research/section/2050-scenarios-fourplausible-futures (Accessed: 3 August 2020).

Burns, C. Cottam, H. Vanstone, C. Winhall, J. (2006) Red Paper 02 Transformation Design Design Council

Carney, J. (2018) The Ten Commandments of Horizon Scanning - Futures, Foresight and Horizon Scanning. Available at: https://foresightprojects.blog.gov.uk/2018/03/08/the-tencommandments-of-horizon-scanning/ (Accessed: 29 July 2020).

Cassidy, T. (2011) 'The Mood Board Process Modeled and Understood as a Qualitative Design Research Tool', Fashion Practice, 3(2), pp. 225-251. doi: 10.2752/175693811X13080607764854.

Centre for Sustainable Fashion (2018) Fashion Futures 2030. Available at: https://www.fashionfutures2030.com/scenarios/home (Accessed: 29 July 2020). 
Design Council UK (2021) The design process: what is the double diamond?, Design Council. Available at: https://www.designcouncil.org.uk/news-opinion/design-process-what-double-diamond (Accessed: 17 august 2021)

Dormer, P. (ed.) (1997) The culture of craft: status and future. Manchester: Manchester University Press (Studies in design).

Drew, D. and Yehounme, G. (2017), The Apparel Industry's Environmental Impact in 6 Graphics. World Resources Institute

Ellen MacArthur Foundation (2017) A New Textiles Economy: Redesigning fashion's future. Available at: http://www.ellenmacarthurfoundation.org/publications (Accessed: 19 March 2019).

Global Fashion Agenda (2017) Pulse of the Fashion Industry 2017.

Government Office for Science (2017) 'The Futures Toolkit: Tools for Futures Thinking and Foresight across UK Government', p. 116.

Hebinck, A. et al. (2018) 'Imagining transformative futures: participatory foresight for food systems change', Ecology and Society, 23(2). doi: 10.5751/ES-10054-230216.

Heron, J. and Reason, P. (1986) Research with people Person-centered Review, 4(1): 456-76.

Heron, J. and Reason, P. (2001) The Practice of Co-operative Inquiry: Research with rather than on people, Handbook of Action Research, first edition, London, Sage, 2001, pp 179-188

Kozlowski, A., Bardecki, M. and Searcy, C. (2019) 'Tools for Sustainable Fashion Design: An Analysis of Their Fitness for Purpose', Sustainability, 11(13), p. 3581. doi: 10.3390/su11133581.

Miaskiewicz, T. and Kozar, K. A. (2011) 'Personas and user-centered design: How can personas benefit product design processes?', Design Studies, 32(5), pp. 417-430. doi:

10.1016/j.destud.2011.03.003.

Polanyi, M. (1967). The Tacit Knowledge Dimension. London: Routledge \& Kegan Paul.

Randers, J. et al. (2018) Transformation is feasible: How to achieve the Sustainable Development Goals within Planetary Boundaries. A report to the Club of Rome for its 50 year anniversary 17 October 2018. Stockholm Resilience Centre, p. 60.

Sainsbury's and Department 22 (2019) 'Future of Food Report', p. 34.

Schwartz, P. (1991). The Art of the Long View. Doubleday/Currency, 1991. University of Michigan.

Tyszczuk, R. (2019) A brief History of Scenarios in Culture and Climate Change Scenarios Tyszczuk, R. Smith, $\mathrm{j}$ and Butler, $\mathrm{R}$ (Eds.) Shed, Cambridge

Van de Ven, A. H. (2007), Engaged Scholarship: A Guide for Organisational and Social Research, Oxford University Press, New York.

Walker, S and Giard, J. (2013) The Handbook of Design for Sustainability, Bloomsbury.

Williams, D. (2018) Fashion Design as a Means to Recognize and Build Communities-in-Place. She-ji: The Journal of Design, Economics and Innovation, 6 (4). pp. 567-568. ISSN 2405-8726 